\title{
Climate Resilience and Regeneration: How Precincts Can Adapt to and Mitigate Climate Change
}

\section{Introduction}

Cities are designed landscapes. Human settlements are typically sited based on natural endowments such as bioregional context, topography, hydrology, and soils, but as the city grows, the artificial subsumes the natural. In response to the overcrowded and unhealthy working conditions of the industrial era, modernist notions of urban design from the late nineteenth to the late twentieth century encouraged a low-density spread of cities to make space for fresh air and gardens. The rise of the car enabled sprawling garden suburbs to spread out across vast hinterlands, ultimately leading to increasingly dysfunctional cities (as described in earlier chapters). There has been increasing call for more compact and sustainable cities, leading to the need for higher-density regenerative redevelopment in both brownfields and greyfields. This chapter examines whether it is possible to not only densify greyfields, as outlined in the model in this book, but to do it in a way that regenerates the natural qualities of the areas being developed-to improve liveability and to build resilience to climate change. 
Urban regeneration can retrofit sprawl to deliver denser urban environments with potential benefits for residents, but contemporary infill development erodes the suburban qualities of open space and greenery that the early Modernists sought to provide. Poorly designed infill degrades the natural qualities of the typically leafy greyfields suburbs. Fragmented knock-down-rebuild infill is resulting in a significant loss of gardens and canopy trees, and simply creates more hard surfaces without a great deal of density. Residents generally are upset at the loss of multiple benefits associated with the natural qualities of the suburbs. But there are ways to design compact urban areas with nature in mind, and there have been examples of this over the centuries. Yet, most major Australian metropolitan planning schemes support infill as small-lot subdivision with an emphasis on aspects other than urban green space, so it is not unexpected to find that the redevelopment of greyfields has come to represent a loss of natural qualities. It is only recently, as governments around the world have recognised the critical role that urban nature can play in climatechange mitigation and climate adaptation, that there has been a surge of urban-planning interest to include nature more explicitly in future city redevelopment. The question is: how?

This chapter describes risks and opportunities climate change presents to urban areas and how nature-based solutions can support GPR, particularly place-activated GPR, to minimise climate vulnerability while maximising liveability.

\section{Metropolitan Climate Projections and Bioregional Considerations}

Climate-change projections (e.g., those from the UN's Intergovernmental Panel on Climate Change and Australia's Bureau of Meteorology) indicate an increasing incidence of extreme climatic conditions across the globe (and Australia) related to increased temperatures, episodes of drought and flooding, bushfires of increased intensity, sea-level rise, exacerbated by storm surges and coastal erosion. In Australia, most population growth is expected to occur in the cities of Melbourne, Sydney, 
Brisbane, and Perth, all located in the southern half of the continent, which is projected to experience longer, dryer, hotter summers and reduced rainfall. Australia is already witnessing these impacts (Norman et al., 2021).

Perhaps the biggest impact is likely to be increased urban heat, especially the extremes that persist during heat waves that intensify urban heat islands, resulting in more deaths than any other natural hazard (Newton et al., 2018). Projections indicate that temperatures above $40{ }^{\circ} \mathrm{C}$ will become more common in the decades ahead (Table 5.1). For example, in Perth the number of days over 40 degrees is projected to increase by $50 \%$ compared to their rate of occurrence in the late twentieth century, and to be around five times more frequent in 2090 under the high emissions projections.

Indeed, in January 2020, Penrith, in western Sydney, reached $48.9^{\circ}$ and was the hottest place on earth that day. The reality is that all Australian cities are moving in this direction. Climate adaptation is going to need to be embedded in all future urban development, whether it is in central city areas, new areas on the urban fringe, or greyfield areas. Thus, this chapter sets out the key features of adaptation.

\section{Climate-Adaptation Strategies}

The recent spate of highly damaging extreme events experienced by Australians in recent times-heatwaves, bushfires, droughts, flooding, and coastal erosion-illustrate the threat multipliers of climate change (Newton et al., 2018) and are demonstrating to the nation's population as never before the severity of such shocks to built environments and human well-being. The impacts of climate change have been the focus of increased applied research by major national research centres and networks this century, exploring policy and planning interventions capable of realising transformative mitigation and adaptation pathways. These include: green urbanism (refer to 100 Resilient Cities network; Fastenrath et al., 2019); options to manage sea-level rise (refer to National Climate Change Adaptation Research Facility; Norman, 2016); and urban cooling and local flood mitigation (refer to CRC for Water Sensitive Cities 


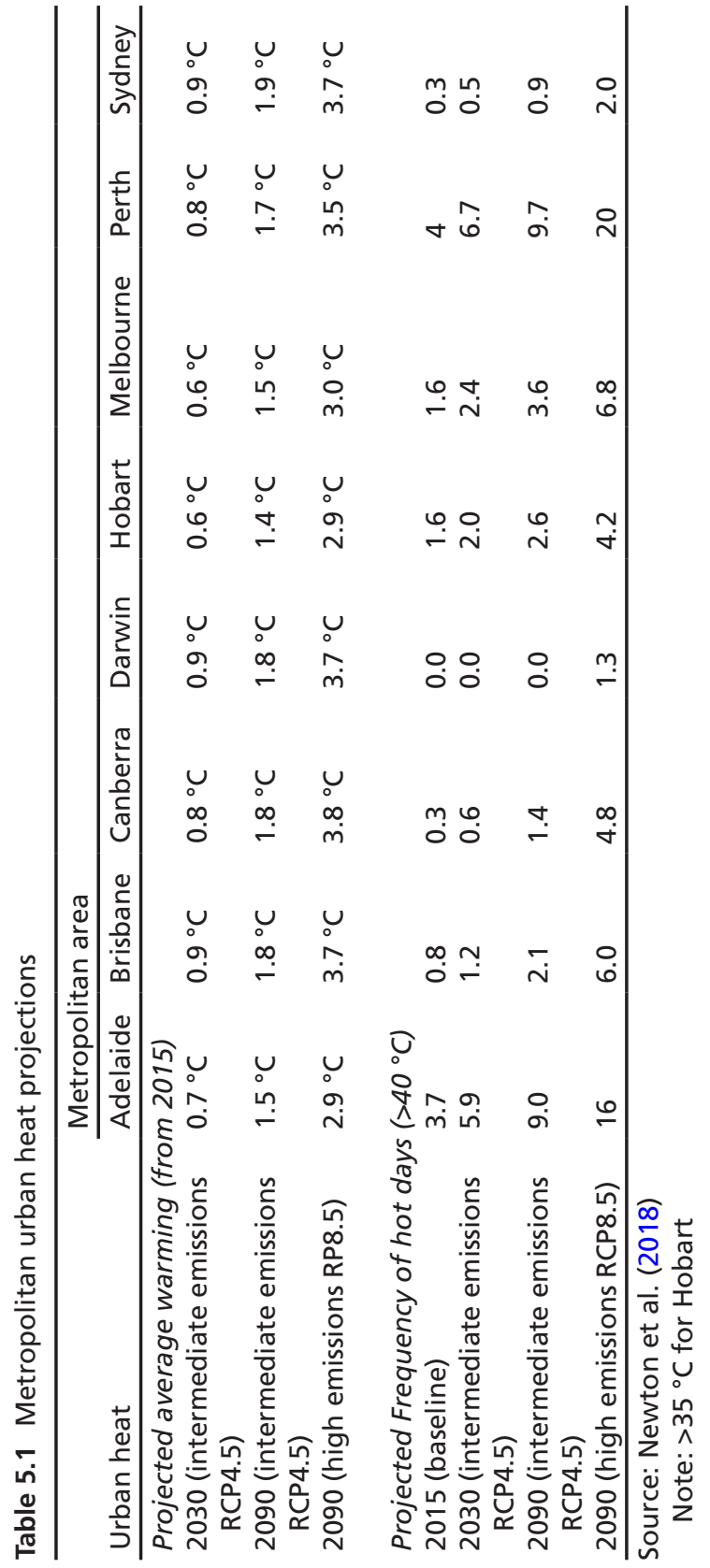


and CRC for Low Carbon Living; Newton \& Rogers, 2020). The first sector to undertake the necessary detailed risk assessment of climatechange impacts on Australia's settlement system was the insurance industry. This represented a major transition over the past 20 years from an exclusive reliance on actuaries and data from historical events to a forward-looking approach that embraced climate science, spatial science, and mathematical modelling. The result has been a detailed small-scale risk-assessment mapping of neighbourhoods across all cities and towns in Australia in relation to properties that are likely to become uninsurable. Such addresses are forecast to rise tenfold in Adelaide between 2019 and 2100 and fivefold in Newcastle and Sydney; and on the Gold Coast by the end of the century one in six properties will be uninsurable (ABC, 2020).

At present, governments tend to maintain a largely reactive disastermanagement stance to extreme events. This needs to transition to proactive strategies involving climate-adaption planning and redesign of vulnerable urban landscapes. A high proportion of these will be in greyfields. Here, increasing pressure will be applied by industries, workplaces, and residents located in at-risk areas for governments to ensure that future urban development responds to a new set of urban-design principles. Planning intervention at a precinct scale-such as GPR-will enable such a sustainablity transition to occur.

\subsection{Benefits of Urban Nature}

Despite there being numerous benefits to incorporating nature into urban areas, most planning regulations emphasise the built form over urban nature, whereby urban open space becomes increasingly dominated by concrete, asphalt, and other hardscapes. A major challenge is where and how to (re)integrate nature into cities, especially in large and densely developed cities where little space can be found; justifying the preservation of urban nature may be difficult because pressure is high for other land uses (e.g., a greater supply of affordable housing, parking, or additional commercial buildings required for local job creation in the 
suburbs). The gradual loss of urban nature in infill areas is insidious, but not inevitable. It is a question of design. Numerous approaches emphasise the design of nature into the city (Frantzeskaki 2020); key concepts are summarised in Box 5.1, which can all be quantified for climateadaptation risk assessment.

\section{Box 5.1 Urban Nature Terminology}

Ecosystem services are the benefits humans obtain from nature. There are many such 'services', such as flood mitigation, urban cooling, nutrient cycling, pollution removal, and food production. Preserving, maintaining, and regenerating nature within cities through an appropriate landscape structure can maximise these low-cost, high-benefit ecosystem services (Breuste et al., 2020). The integration of ecosystem services in the city is often referred to as green and blue infrastructure.

Green and blue infrastructure: within cities includes a range of urban natural assets, representing a counterpoint to the 'grey infrastructure' of roads, buildings, car parks, and other impervious surfaces that cover large areas of industrial cities of the modern era. 'Green' assets include trees, parks, and gardens, while 'blue' assets include elements of water-sensitive urban design (WSUD), such as rain gardens, remediation of local creeks and drainage channels, and stormwater capture and storage in swales and retention ponds (Victoria State Government, 2017). Collectively, networks of green and blue infrastructure can improve environmental conditions and residents' quality of life.

Biophilia and biophilic urbanism: Biophilia was defined by Wilson (1984) as 'the innate tendency to focus on life and lifelike processes'. Biophilic urbanism has become a major social movement within city policy and practice centred on integration of, and access to, nature in and on buildings, not just between them, for both the ecosystem services it offers and the psycho-social benefits it provides (Beatley, 2011). Biophilic urbanism is quantified in Soderlund and Newman (2015).

Nature-based services/solutions is a more recent term introduced by the World Bank (MacKinnon et al., 2008). It has a broad and inclusive range of actions to protect, sustainably manage, and restore multiple ecosystem services as a means to create resilience to climate change in cities, and thus reduce negative impacts on health and well-being (Elmqvist et al., 2019).

This chapter will use 'nature-based solutions' as an umbrella term for designed and managed urban nature that provides human well-being and biodiversity benefits within an established urban arena such as greyfields. 


\subsection{Planning for Urban Nature-Based Solutions}

This book, along with many other planning sources, highlights the benefits that compact city design offers for urban sustainability. However, a compact city agenda creates a dilemma in that higher-density development affects and often replaces green space. The squeezing out of urban nature, particularly the loss of greenery on private property in greyfields suburbs through recent urban intensification, has been extensive, although redeveloped inner areas have at the same time become greener in their public spaces, especially in wealthier suburbs. Thus, it is possible to design a greater level of greening into greyfields using both public and private spaces. If this is not achieved, the city may continue to spiral down in its greening and the demand for prime greenfield land will continue unabated. Increasingly, innovative designers are finding ways to integrate urban greenery into high-density areas, and the possibility for green infrastructure to grow not just between buildings, but upon and over them is now evident. But how? Section 4 of this chapter discusses planning for urban nature that can at the same time be planning for urban density (Thomson \& Newman, 2021).

Natural systems are not constrained by administrative boundaries such as property title, neighbourhood, municipality, or even city, and thus they should not be considered at these fragmented levels. Natural systems must be considered at a range of scales - macro (city, catchment), meso (municipality, precinct), and site (individual lot) — that work toward the creation of a connected city-wide green and blue infrastructure network.

Climate adaptation for sea-level rise, flooding events, and bushfires need to be dealt with at national- and local-scale planning (Norman et al., 2021), but may be considered at the level of smaller hydrological subsystems: watershed (catchment), aquifer, or site. Trees can form vast forests, but in the city context a patch of trees may form a small ecology of its own or contribute to an ecological corridor of linked sites across a city. Planning for urban nature requires (eco-)systems thinking. Each of these scales has a relationship to urban planning: 
- The macro scale should respond to bioregional considerations such as widespread drainage patterns; for example, 'city as catchment' (Kenway \& Tjandraatmadja, 2009), coastal areas at risk of sea-level rise or lowlying sites at risk of flooding (Norman, 2009), or large, intact ecosystems that represent relatively cohesive natural landscape divisions worthy of protection. This macro-scale setting will often be larger than the development footprint of the city (such as a riparian corridor or the broader metropolitan catchment) and should form the reference point for decisions at the smaller scales described below.

- The meso scale could be considered as the regional open-space structure that preserves high-value landscapes, watercourses with riparian buffers, and other ecologically or aesthetically important landscape features. Planning at this scale is important to support city-scale interaction with urban nature.

- The micro scale comprises individual plots, blocks, and streets: the cellular pieces that collectively make up the vast bulk of any city. The cumulative actions taken at this fine grain are most relevant when considering urban infill.

Although the macro and meso scales are predominantly shaped by policy planners, at the micro scale most decisions are made by developers and designers, who can organise a site to design nature either in or out; therefore, this scale is most relevant to GPR. Australian cities are witnessing considerable piecemeal infill development involving a miriad of micro-scale decisions, all of which are currently accommodated within existing building and planning regulations. The result is small-lot subdivision that typically leads to incremental displacement and disruption of natural assets. However, planning mechanisms can be employed to ensure that each of the micro-scale decisions work toward the incremental improvement of urban nature. Local government development assessment instruments and capabilities are critical here: but remain under resourced due to vertical fiscal imbalance in Australia's system of government (Tomlinson \& Spiller 2018). 


\section{$4 \quad$ Integrating Nature-Based Solutions at the Precinct Scale}

\subsection{Water}

In a drier climate, water scarcity will become an increasing problem for some cities. But the demand for potable water can be greatly reduced through water-efficiency measures as well as water harvesting from rainwater and stormwater collection, and recycling wastewater. All of these water sources can be used to help regenerate aquifers and water bodies in the bioregion. In fact, the whole city can be designed as a catchment. Rather than expel water through concrete channels and pipes (grey infrastructure) to the sea, water sensitive urban design (WSUD) seeks ways to funnel and manage stormwater flows to the benefit of the city. WSUD aims to balance urban water flows with natural water flows that existed before urban development. In the hot, dry climate experienced across much of Australia, WSUD may include strategies to hold water (e.g., in wetlands and detention basins) for future uses such as irrigation; or through swales, rain gardens, sumps, and other passive water-retention techniques to slow the rate of runoff, thus reducing urban flood risk while also recharging soil moisture and deeper aquifers. This is the sponge city concept.

Many of these techniques are best achieved at the regional scale; however, it is possible to design-in on-site measures that replicate these approaches at the smaller scale, such as 'deep-soil' gardens or green roofs to absorb rainfall at source or small-scale water detention (e.g., rainwater tanks) or greywater treatment. For these reasons it is advantageous to (i) ensure integrated site design that includes WSUD measures, (ii) amalgamate lots to enable greater potential for accommodating WSUD features and to ameliorate the cost over a larger number of dwellings, and (iii) consider developer bonuses for on-site WSUD to incentivise developer-led responses and to reduce public costs on engineering work to address stormwater flows from infill developments.

Site-scale decisions when extrapolated to the city scale have major impacts, either positive or negative, on urban nature. Using the methodology developed by the CRC for Water-Sensitive Cities Urban Infill 

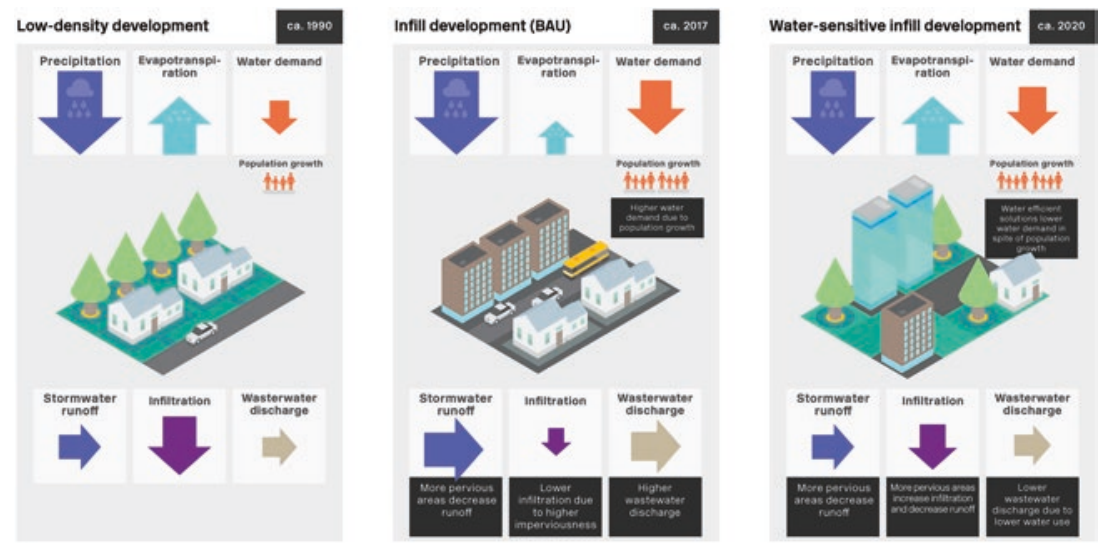

Fig. 5.1 Water-sensitive infill development for small-scale precincts. (Source: Renouf \& Sochacka, 2018; London et al., 2020)

Integrated Research Project (Renouf et al., 2020; Renouf \& Sochacka, 2018), it is now possible to quantitatively assess the nature-based impact of new urban-development projects on key landscape features such as surface imperviousness, groundwater infiltration, stormwater runoff, changes in green space and canopy tree coverage, evapotranspiration, and urban heating. Figure 5.1 shows various outcomes for business-as-usual infill versus water-sensitive infill, with significant differences in outcome resulting from different site arrangement of buildings, carparking, driveways, and setbacks. More coordinated place-activated GPR approaches can deliver a high site yield and larger areas of green space, while small-lot subdivision with larger building footprints, setbacks on all sides, and large driveways and garages may satisfy minimum planning open-space requirements, yet remove almost all urban nature on private plots. Municipalities are increasingly left to address nature-based solution deficits on limited public land with limited public funds. A good, welldesigned place-activated GPR will have spaces on-site where green-blue infrastructure can enable multiple benefits. Nature-based assessments of urban infill are currently missing from local government developmentassessment processes but are applied for the first time in a case study in Chap. 7 to illustrate the regenerative benefits of precinct-scale redevelopment compared to historical and current business-as-usual small-lot subdivision development. 


\subsection{Urban Heat}

In urban environments, building materials like concrete, bitumen, and metal with high thermal mass absorb heat; pavements and rooftops can also absorb heat to varying degrees (e.g., a dark-versus light-coloured roof). This solar gain combined with the generation of heat within the city itself from sources such as car exhaust and air conditioning tends to result in greater heat than in the surrounding non-urban environments. This can be readily revealed through extensive urban heat mapping now commonly undertaken as part of strategic municipal land-use planning (Ding et al., 2020). This 'urban heat island' effect is exacerbated by global warming, and studies across the world's major cities show that an urban heat island increases city temperatures between $2{ }^{\circ} \mathrm{C}$ and $12{ }^{\circ} \mathrm{C}$ compared to their rural surroundings (Osmond \& Sharifi, 2017).

Urban heat can be reduced through a range of methods such as: (a) high albedo, reflective surfaces (e.g., the Queensland city of Townsville reduced the average air conditioning load by $10 \%$ over a decade when they issued a regulation requiring that all roofs be white); and (b) urban greening, which both shades surfaces that otherwise absorb heat (such as concrete and roads) and actively cools through evapo-transpiration. The cooling effect of greenery increases with canopy cover and vegetation type. Osmond and Sharifi (2017) identify a range of urban cooling strategies for precincts (Fig. 5.2):

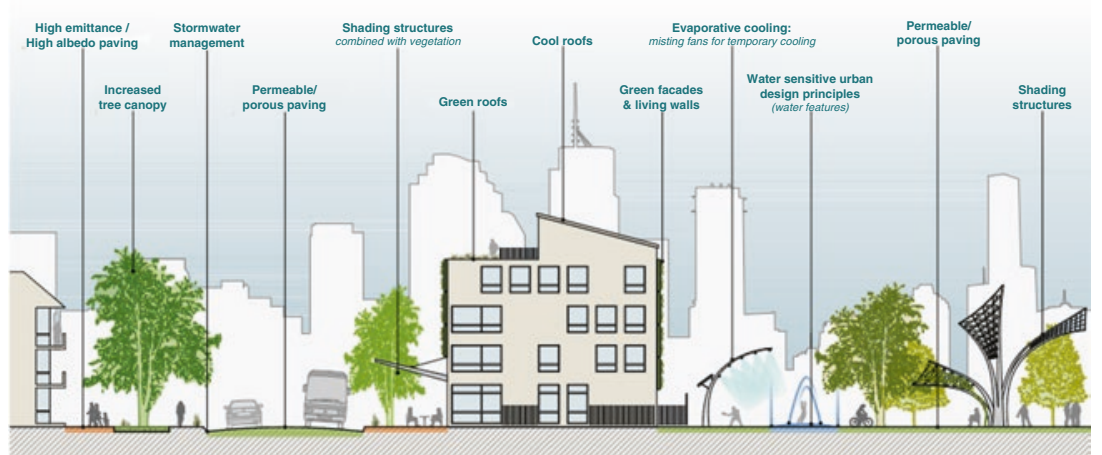

Fig. 5.2 Cooling strategies for urban precincts during summer. (Source: Osmond \& Sharifi, 2017) 
- Maximise green infrastructure in the public realm through additional well-irrigated street canopy trees and rain gardens and move power cabling underground to improve tree canopy coverage.

- Optimise private and public green space, including green roofs and vertical greenery; use permeable materials in paving.

- Install shading devices for (double-glazed) windows.

Buildings also need to play their part, both individually and as positioned within a precinct, to optimise solar access, shading, and natural ventilation. CSIRO has developed the Nationwide House Energy Rating Scheme software (NatHERS) for assessing the thermal design performance of residential buildings, which is now mandated in the Building Code of Australia and currently set at a minimum of six-star performance (amount of artificial heating and cooling required to keep temperatures inside a dwelling within a comfortable range). Designs capable of attaining seven or more stars are readily available (https://www.nathers.gov.au/ owners-and-builders/7-star-house-plans), and when combined with solar photovoltaic power enable transition to zero-emission dwellings (Deng $\&$ Newton, 2017). These are design principles employed in the case study precinct design and assessment featured in Chap. 7.

\subsection{Urban Vegetation}

Vegetation loss as a result of urban infill is a major problem in Australian cities (Hurley et al., 2020). To counteract vegetation loss on private land, many councils are looking to maximise planting in the public realm. Dense and layered tree and shrub planting along streets can help increase shading, air purification, cooling, and noise reduction and slow the rate and speed of stormwater runoff to reduce urban flood risk. Tree-canopy targets are usually the central focus for urban-greening or urban-forest strategies. The City of Melbourne, for example, has a target of $40 \%$ canopy cover on public land by 2040 (Croeser et al., 2020). Planting guidelines can specify climate-appropriate vegetation to reduce future maintenance needs and reduce irrigation demand.

In precinct-scale developments, site layout can help find space for gardens by requiring some building setbacks (most likely rear setbacks), and 
planning can mandate space for trees on private land through development controls such as deep soil zones (cf. NSW SEPP 65). Larger sites allow greater flexibility for site planning so that building and grey infrastructure can be arranged to maximise on-site green infrastructure. Precinct regeneration on larger sites ideally provides opportunity for a redistribution of street space to green space and reactivation for resident use (Chap. 7). For example, WGV Perth set targets for the infill development to match the tree-canopy coverage measured at the former school and playing grounds prior to the redevelopment in 2014. WGV set a tree-canopy target across the development site of $30 \%$ at 15 years postconstruction, with a tree-canopy diameter of $6 \mathrm{~m}$ (Byrne et al., 2020). In denser urban areas, such as those where transit-activated GPR is appropriate, it is also possible for urban greenery to be integrated on, in, and over built structures; for example, as integrated greenwalls and green roofs that serve as biophilic facades on buildings (Newman, 2014; Thomson \& Newman, 2021).

\section{Conclusion}

Climate projections offer planners increased clarity about potential risks of climate change, and consequently what impacts to plan for. Integrated design that is central to place-activated and transit-activated GPR needs to incorporate nature-based solutions to increase not only livability, but also resilience to climate change. The many nature-based solutions identified in this chapter are an affordable insurance policy against climate shocks that also help create more attractive, more valuable, more biodiverse, and more sustainable communities. The IPSOS (2020) survey closest to the time of the Australian bushfires revealed that environmental concerns had risen to be the top issue among Australia's population wanting action on climate change. Place-activated greening of the greyfields needs to be innovative in improving urban infill through regenerating precincts in relation to better urban design densities and better natural urban environment qualities. 


\section{References}

ABC. (2020). The rise of red zones of risk. https://www.abc.net.au/ news/2019-10-23/the-suburbs-facing-rising-insurance-costs-fromclimate-risk $/ 11624108$ ? $\mathrm{nw}=0$

Beatley, T. (2011). Biophilic cities: Integrating nature into urban design and planning. Island Press.

Breuste, J., Artmann, M., Ioja, C., \& Oureshi, S. (2020). Making green cities: Concepts, challenges and practice. Springer.

Byrne, J., Taylor, M., Wheeler, T., \& Breadsell, J. K. (2020). WGV: Quantifying mains sater savings in a medium density infill residential development. Sustainability, 12(16), 6483. https://doi.org/10.3390/su12166483

Croeser, T., Ordóńez, C., Threlfall, C., Kendal, D., van der Ree, R., Callow, D., \& Livesley, S. J. (2020). Patterns of tree removal and canopy change on public and private land in the City of Melbourne. Sustainable Cities and Society, 56(January), 102096.

Deng, G., \& Newton, P. (2017). Assessing the impact of solar PV on domestic energy consumption: Exploring the prospect of rebound effects. Energy Policy, 110, 313-324.

Ding, L., Petersen, H., Craft, W., Santamouris, M., Prasad, D., Osmond, P., Walton, R., McKellar, S., \& O’Reilly, D. (2020). Cooling South Melbourne: Impact analysis of cooling interventions. http://uhimitigationindex.be.unsw. edu.au/static/files/Cooling\%20South\%20Melbourne\%2019-11-20.pdf

Elmqvist, T., Gatzweiler, F., Lindgren, E., \& Liu, J. (2019). Resilience management for healthy cities in a changing climate. In M. Marselle, J. Stadler, J. Korn, K. Irvine, \& A. Bonn (Eds.), Biodiversity and health in the face of climate change (pp. 411-425). Springer Open.

Fastenrath, S., Coenen, L., \& Davidson, K. (2019). Urban resilience in action: The Resilient Melbourne Strategy as transformative urban innovation policy? Sustainability, 11(3), 693.

Frantzeskaki, N., Vandergert, P., Connop, S., Schipper, K., Zwierzchowska, I., Collier, M., \& Lodder, M. (2020). Examining the policy needs for implementing nature-based solutions in cities: Findings from city-wide transdisciplinary experiences in Glasgow (UK), Genk (Belgium) and Poznań (Poland), Land Use Policy, Vol. 96 (Jul 2020), 104688.

Hurley, J., Saunders, A., Boruff, B., Duncan, J., Knight, G., Amati, M., Sun, C. Caccetta, P., \& Chia, J. (2020). Benchmarking urban vegetation cover: Melbourne, Perth Sydney. Clean Air and Urban Landscape Hub, Melbourne, Australia. 
IPSOS. (2020). Australians' environmental concerns in January 2020. https:// www.ipsos.com/en-au/australians-environmental-concerns-january-202

Kenway, S., \& Tjandraatmadja, G. (2009). Technological innovation in the provision of sustainable urban water services. In P. Newton, K. Hampson, \& R. Drogemuller (Eds.), Technology, design and process innovation in the built environment (pp. 267-289). Spon Press.

London, G., Bertram, N., Renouf, M., Kenway, S. J., Sainsbury, O., Todorovic, T., Byrne, J., Pype, M. L., Sochacka, B., Surendran, S., \& Moravej, M. (2020). Water sensitive outcomes for infill development. Final Draft. CRC for Water Sensitive Cities.

MacKinnon, K., Sobrevila, C., \& Hickey, V. (2008). Biodiversity, climate change, and adaptation: Nature-based solutions from the World Bank portfolio (No. 46726, pp. 1-112). The World Bank.

Newman, P. (2014). Biophilic urbanism: A case study of Singapore. Australian Planner, 51, 47-65. https://www.tandfonline.com/doi/full/10.1080/ 07293682.2013 .790832

Newton, P., \& Rogers, B. (2020). Transforming built environments: Towards carbon neutral and blue-green cities. Sustainability, 12, 4745.

Newton, P., Bertram, N., Handmer, J., Tapper, N., Thornton, R., \& Whetton, P. (2018). Australian cities and the governance of climate change. In R. Tomlinson \& M. Spiller (Eds.), Australia's metropolitan imperative (pp. 193-211). CSIRO Publishing.

Norman, B. (2009). Principles for an intergovernmental agreement for coastal planning and climate change in Australia. Habitat International, 33(3), 293-299.

Norman, B. (2016). Climate ready cities. Policy Information Brief 2. National Climate Change Adaptation Research Facility.

Norman, B., Newman, P., \& Steffen, W. (2021). Apocalypse now: Australian bushfires and the future of urban settlements. Nature Urban Sustainability, 1(2), 1-9.

Osmond, P., \& Sharifi, E. (2017). Guide to urban cooling strategies. CRC for Low Carbon Living.

Renouf, M., \& Sochacka, B. (2018). Integrated Research Project 4 - Water sensitive outcomes for infill developments. CRC for Water Sensitive Cities.

Renouf, M., Kenway, S., Bertram, N., London, G., Sainsbury, O., Todorovic, T., Nice, K. A., Surendran, S., \& Moravej, M. (2020). Water sensitive outcomes for infill development. CRC for Water Sensitive Cities. 
Soderlund, J., \& Newman, P. (2015). Biophilic architecture: A review of the rationale and outcomes. AIMS Environmental Science, 2(4), 950-969.

Thomson, G., \& Newman, P. (2021). Green infrastructure and biophilic urbanism as tools for integrating resource efficient and ecological cities. Urban Planning, 6(1), 75-88. https://doi.org/10.17645/up.v6i1.3633

Tomlinson, R., \& Spiller, M. (2018). Australia's metropolitan imperative. CSIRO Publishing.

Victoria State Government. (2017). Planning a Green-Blue City. Department of Environment, Land, Water and Planning, Victorian State Governemnt. Wilson, E. (1984). Biophilia. Harvard University Press.

Open Access This chapter is licensed under the terms of the Creative Commons Attribution 4.0 International License (http://creativecommons.org/ licenses/by/4.0/), which permits use, sharing, adaptation, distribution and reproduction in any medium or format, as long as you give appropriate credit to the original author(s) and the source, provide a link to the Creative Commons licence and indicate if changes were made.

The images or other third party material in this chapter are included in the chapter's Creative Commons licence, unless indicated otherwise in a credit line to the material. If material is not included in the chapter's Creative Commons licence and your intended use is not permitted by statutory regulation or exceeds the permitted use, you will need to obtain permission directly from the copyright holder.

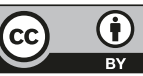

